\title{
Study of Radiative Defects Using Current-Voltage Characteristics in ZnO Rods Catalytically Grown on 4H-p-SiC
}

\author{
N. Bano, ${ }^{1}$ I. Hussain, ${ }^{1}$ O. Nur, ${ }^{1}$ M. Willander, ${ }^{1}$ and P. Klason ${ }^{2}$ \\ ${ }^{1}$ Department of Science and Technology, Norrköping Campus, Linköping University, 60174 Norrköping, Sweden \\ ${ }^{2}$ Department of Physics, Gothenburg University, 41296 Gothenburg, Sweden \\ Correspondence should be addressed to N. Bano, narba@itn.liu.se
}

Received 22 February 2010; Revised 10 May 2010; Accepted 21 June 2010

Academic Editor: Ali Eftekhari

Copyright $\odot 2010$ N. Bano et al. This is an open access article distributed under the Creative Commons Attribution License, which permits unrestricted use, distribution, and reproduction in any medium, provided the original work is properly cited.

\begin{abstract}
High-quality $\mathrm{ZnO}$ rods were grown by the vapour-liquid-solid (VLS) technique on $4 \mathrm{H}$-p-SiC substrate. The current transport mechanisms of the diodes at room temperature (RT) have been explained in term of the space-charge-limited current model based on the energy band diagram of $\mathrm{ZnO}$ rods $/ 4 \mathrm{H}-\mathrm{p}$-SiC heterostructure. The tunneling mechanism via deep-level states was found to be the main conduction process at low-applied voltage but at trap-filled limit voltage $\mathrm{V}_{\mathrm{TFL}}$ all traps are filled and the space-chargelimited current conduction dominated the current transport. From the RT current voltage measurements, the energy of the deep level trap and the trap concentration were obtained as $\sim 0.24 \pm 0.02 \mathrm{eV}$ and $4.4 \times 10^{18} \mathrm{~cm}^{-3}$, respectively. The deep level states observed correspond to zinc interstitial $\left(\mathrm{Zn}_{\mathrm{i}}\right)$, responsible for the violet emission.
\end{abstract}

\section{Introduction}

Zinc oxide $(\mathrm{ZnO})$ with wurtzite structure has a large direct bandgap around $3.4 \mathrm{eV}$, and a large exciton binding energy $(60 \mathrm{meV})$, has recently attracted global interest, especially in its nanostructure form [1]. This material is famous for its photonic and electronic applications such as UV light emitters/detectors and as high-power and high-temperature devices [2, 3]. ZnO has a number of other advantages compared to other wide band gap semiconductors including high-thermal/chemical stabilities; the possibility of wet chemical etching and existence of large area wafers have all led to the demonstration of $\mathrm{ZnO}$ as an alternative material to nitride semiconductors $[2,4]$. Moreover, $\mathrm{ZnO}$ in its nanostructure form possesses self-organization growth property which facilitates the growth of $\mathrm{ZnO}$ nanostructures on any substrates such as glass, plastic, $\mathrm{Si}, \mathrm{GaN}, \mathrm{AlGaN}$, and $\mathrm{SiC}$. Among these materials $4 \mathrm{H}-\mathrm{SiC}$ is a good candidate for the growth of $\mathrm{n}-\mathrm{ZnO}$ rods because it has a similar energy bandgap.

$\mathrm{ZnO}$ possesses a rich family of nanostructures such as nanorods (NRs), nanoparticles, nanotips, and nanoneedles, as some examples [2, 5-7]. All such nanostructures have been successfully synthesized and have attracted interest because they can be used as building blocks for different future optoelectronic devices. These nanostructures have many advantages among which are large surface area to volume ratio, good crystal quality and unique photonic properties $[8,9]$. So far, among these structures, rods of $\mathrm{ZnO}$ is grown with relatively better crystalline quality with lower defect density compared to bulk and thin films due to their small foot print and the release of strain and stress due to the large surface area to volume ratio. At the same time, both ends of $\mathrm{ZnO}$ rods are extremely smooth, making them perfect mirror planes and vertical rods are like natural waveguide cavities for making the emitted light to travel to the top of the device, also minimizing partial leakage and thus enhancing the light extraction efficiency from the surface [10]. The dominant radiative defects in $\mathrm{ZnO}$ are oxygen vacancies $\left(V_{O}\right)$, zinc vacancies $\left(V_{Z n}\right)$, zinc interstitials $\left(Z_{i}\right)$, oxygen interstitials $\left(\mathrm{O}_{\mathrm{i}}\right)$, zinc antisites $(\mathrm{ZnO})$, and other extrinsic impurities [11]. The free carrier concentration and luminescence efficiency are directly or indirectly related to these defects [11]. ZnO rods-based optical/electrical devices depend upon the defect chemistry and the understanding of the electrical properties, both of which are the subject of present theoretical and experimental studies. It is therefore essential to study the electrical transport properties of $\mathrm{ZnO}$ 


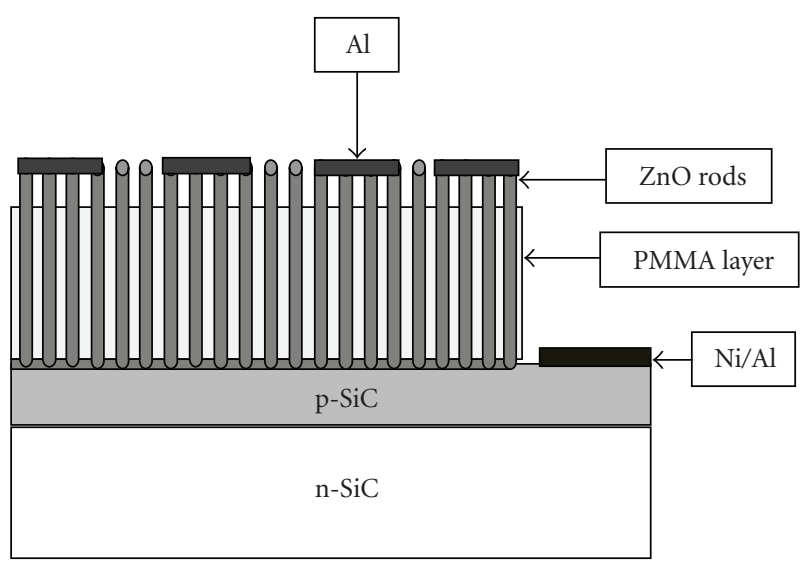

FIGURE 1: Schematic illustration of $\mathrm{ZnO} / \mathrm{p}$-SiC rods heterostructure device.

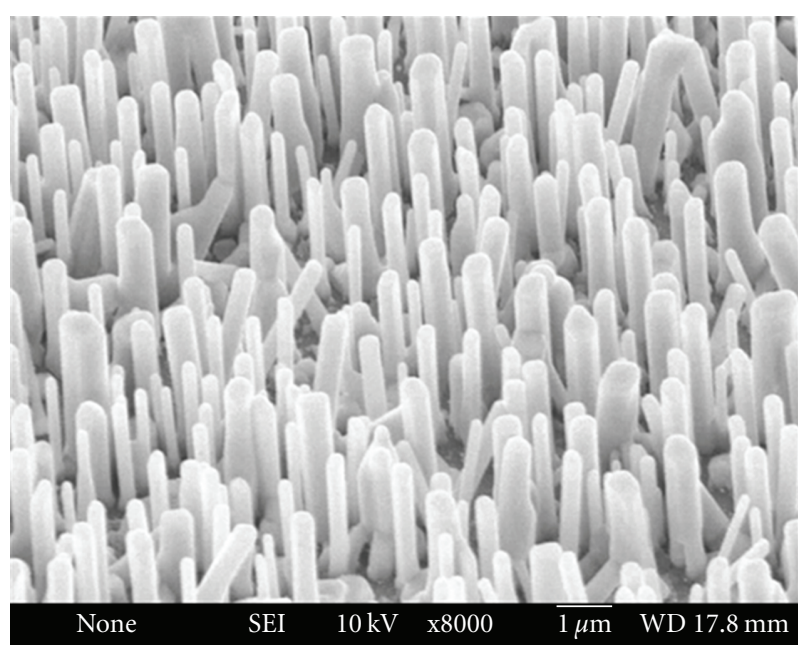

FIGURE 2: SEM image of $\mathrm{ZnO}$ rods grown on $4 \mathrm{H}-\mathrm{SiC}$ substrate.

rods to establish $\mathrm{ZnO}$ rods-based devices. The electrical transport mechanism in $\mathrm{ZnO}$ rods grown on $\mathrm{SiC}$ has not yet been extensively studied nor thoroughly understood. However, to our best knowledge, only few authors reported electrical characteristic of $\mathrm{ZnO}$ thin films and rods on $\mathrm{Si}, \mathrm{SiC}$, and polymer substrates [12-15].

In this study, we report the investigation of the current transport mechanism of $\mathrm{ZnO}$ rods / $\mathrm{p}-\mathrm{SiC}$ heterojunction diode at room temperature (RT) in terms of the spacecharge-limited current model based on the energy band diagram of the heterostructure. From the RT current voltage measurements, the energy of the dominating deep level trap and its trap concentration were also calculated.

\section{Experimental}

$\mathrm{ZnO}$ rods were grown on a p-type $\mathrm{SiC}$ thin film. The ptype $\mathrm{SiC}$ film was grown by conventional chemical vapour deposition (CVD) technique on $\mathrm{n}-\mathrm{SiC}$ commercial substrate [16]. The acceptor concentration in the $\mathrm{p}-\mathrm{SiC}$ thin film was around $5 \times 10^{18} \mathrm{~cm}^{-3}$ and the thickness was around
$1 \mu \mathrm{m}$. The $\mathrm{ZnO}$ rods were grown by the vapour-liquid-solid (VLS) technique. First we cover a small portion of the p-SiC substrate for defining ohmic contacts on the p-SiC. After that a layer of $5 \mathrm{~nm}$ thick Au film was deposited on the p-type SiC. Then $\mathrm{ZnO}$ (99.99\%) powder was mixed with graphite (99.99\%) powder with 1:1 ratio with respect to the weight. This mixed powder was then vaporized. The substrate coated with $\mathrm{Au}$ was placed above the mixture, with the catalyst pointing towards to $\mathrm{ZnO}$ and graphite mixed powder. The growth was carried out in a horizontal tube furnace and the boat was placed in the middle of the quartz tube. To maintain a stable environment inside the tube, a constant $\mathrm{Ar}$ gas flow of $80 \mathrm{sccm}$ was applied for 5-10 minutes. Then the growth was initiated at $890^{\circ} \mathrm{C}$ and continued for 30 minutes. After growth the samples were processed for devices. For the ohmic contact on substrate first we cleaned the small portion of the $\mathrm{p}$-SiC which was covered before the growth of the $\mathrm{ZnO}$ rods after that a thin layer of $\mathrm{Ni} \backslash \mathrm{Al}$ was used. The contact was annealed at $900^{\circ} \mathrm{C}$ for 3 minutes in $\mathrm{Ar}$ atmosphere. Prior to the ohmic contacts on the $\mathrm{ZnO}$ rods an insulating PMMA layer was deposited between the rods. To ensure that no PMMA was on the top of the rods oxygen plasma cleaning was performed prior to the contact metal deposition. Then Al contacts of a diameter $0.5 \mathrm{~mm}$ were evaporated onto a group of rods. The configuration of the device is illustrated schematically in Figure 1. The device structure was characterized by scanning electron microscope (SEM) and at room temperature (RT) using two-point probe current-voltage (I-V) characteristics.

\section{Results and Discussion}

The $\mathrm{ZnO}$ rods were grown vertically aligned as shown in the SEM image in Figure 2. The diameter of the grown $\mathrm{ZnO}$ rods was found to be $200 \mathrm{~nm}$ and up to close to $600 \mathrm{~nm}$, while the length was found to be around $1.9 \mu \mathrm{m}$. Figure 3 shows an equilibrium energy band diagram of $\mathrm{p}-\mathrm{n}$ heterojunction of $\mathrm{p}-4 \mathrm{H}-\mathrm{SiC}$ and $\mathrm{n}-\mathrm{ZnO}$. Here the bandgap $(\mathrm{Eg})$ of $\mathrm{ZnO}$ is $3.3 \mathrm{eV}$ and that of $4 \mathrm{H}-\mathrm{SiC}$ is $3.23 \mathrm{eV}$. The conduction band offset $\left(\Delta \mathrm{E}_{\mathrm{C}}\right)$ for electrons is $\Delta \mathrm{E}_{\mathrm{C}}=\chi \mathrm{ZnO}-\chi \mathrm{SiC}=0.3 \mathrm{eV}$, where $\chi$ is the electron affinity. While the valance band offset $\left(\Delta \mathrm{E}_{\mathrm{V}}\right)$ for holes is $\Delta \mathrm{E}_{\mathrm{V}}=\mathrm{Eg}(\mathrm{ZnO})+\Delta \mathrm{E}_{\mathrm{C}}-\mathrm{Eg}(\mathrm{SiC})=0.4 \mathrm{eV}$. $\Delta \mathrm{E}_{\mathrm{V}}$ has a higher value than $\Delta \mathrm{E}_{\mathrm{C}}$, which means that electron injection from $\mathrm{n}-\mathrm{ZnO}$ to $\mathrm{p}-\mathrm{SiC}$ is larger than hole injection from $\mathrm{p}-\mathrm{SiC}$ to $\mathrm{n}-\mathrm{ZnO}$ [12].

Figure 4 show that the resulting heterojunction exhibited good rectifying $I-V$ characteristics. Such type of rectification behavior is best described by the thermionic emission theory. According to this theory, the current in such device could be expressed as

$$
I=I_{s}\left[\exp \left(\frac{q\left(V-I R_{s}\right)}{n k T}\right)-1\right]
$$

where $I_{s}$ is the saturation current, $R_{s}$ is the series resistance, $k$ is the Boltzmann constant, $T$ is the absolute temperature, $q$ is the elementary electric charge, $V$ is the applied voltage, and $n$ is the ideality factor. 


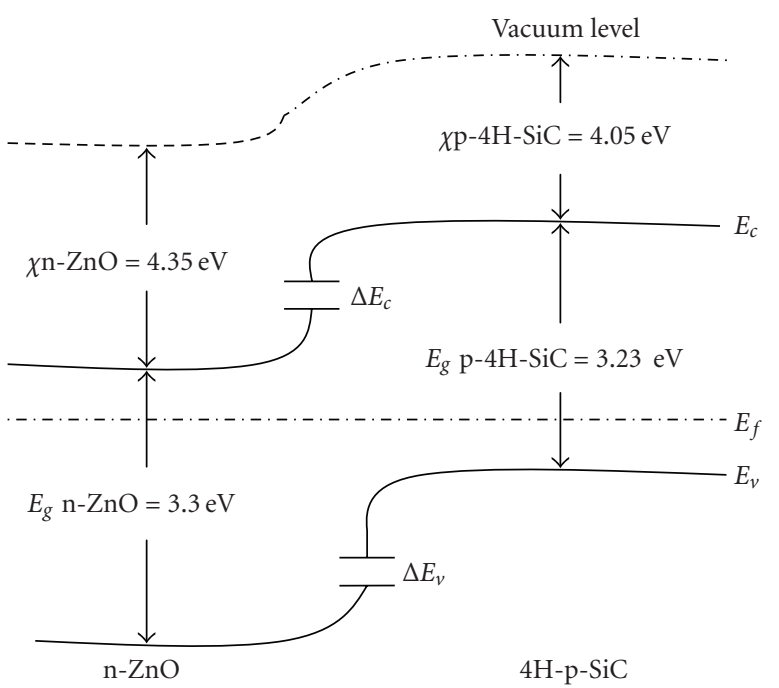

FIgURE 3: It shows a typical fabricated band diagram of $p-n$ hetero junction of $4 \mathrm{H}-\mathrm{p}-\mathrm{SiC}$ and $\mathrm{n}-\mathrm{ZnO}$.

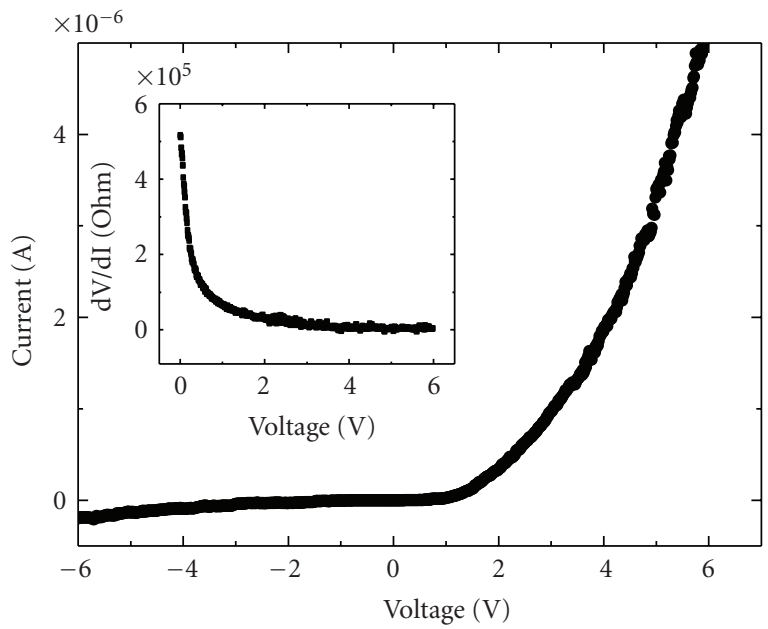

Figure 4: Typical current-voltage characteristics for $\mathrm{ZnO}$ rods and the inset is the diode resistance $\mathrm{dV} / \mathrm{dI}$ as a function of voltage.

The diode series resistance defined as $R_{s}=d V / d I$ is shown in Figure 4 (Inset). Below the turn-on voltage, $R_{s}$ decreases with increasing the forward bias. Then it maintains a constant value above the turn-on voltage. Under the forward bias the conduction band barrier will be decreased and will enhance the electron flow from the $\mathrm{n}-\mathrm{ZnO}$ to the $\mathrm{p}-\mathrm{SiC}$ and holes from the $\mathrm{p}-\mathrm{SiC}$ to the $\mathrm{n}-\mathrm{ZnO}$. The successive recombination would give rise to the forward bias current flow. This means that the diode resistance would firstly decrease upon the increase of the forward bias voltage (i.e., the lowering of the barrier). As the forward bias is large enough, the barrier is negligible; the diode resistance becomes constant, which is due to the bulk material series resistance [17]. The slow rise in the forward current under low bias could be explained by the division of the voltage of the nonideal contact between the $\mathrm{Al}$ electrode and $\mathrm{ZnO}$ rods.

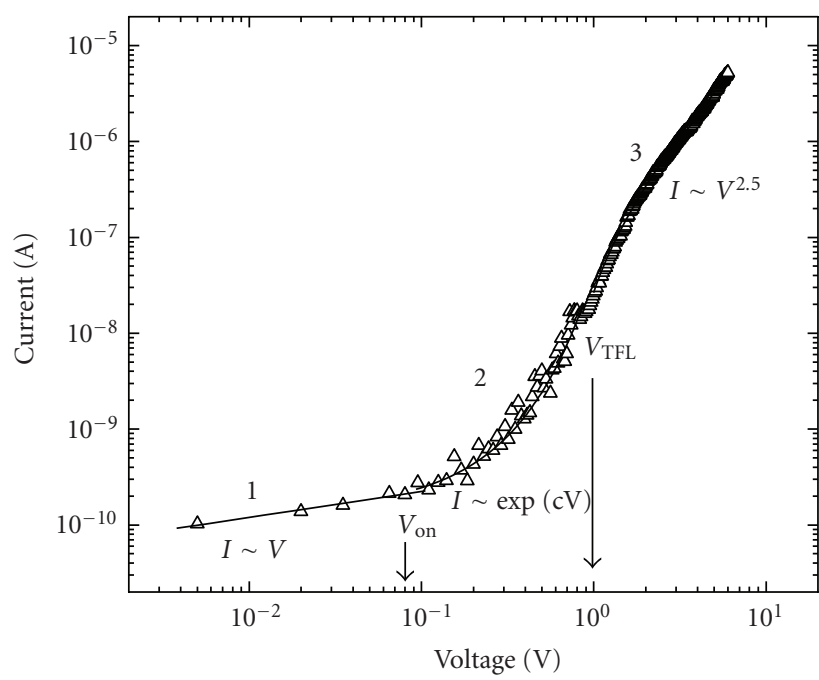

FIgURE 5: Log-log plot for the I-V data of $\mathrm{ZnO}$ rods.

Using different diodes (5 diodes) the ideality factor obtained from (1) was found to be in the range 3-4. The higher value of the ideality factor indicates that the transport mechanism is no longer dominated by the thermionic emission. Nonideal behavior is often attributed to defect states in the band gap of the semiconductor providing other current transport mechanisms such as structural defects, surface contamination, barrier tunneling, or generation recombination in the space charge region and to variations in the interface composition $[18,19]$. To understand which mechanisms influence the junction behavior, the $I-V$ characteristics of the device are studied in a log-log scale.

The log-log plot of the $I-V$ data at RT is shown in Figure 5 and it illustrates that the current transport mechanism is exhibited in three different regions. The current in region 1 follows a linear dependence, that is, $\mathrm{I} \sim \mathrm{V}$. This is an indication that the current transport is dominated by tunneling at low voltages. The boundary for this region was determined to be below $0.06 \mathrm{~V}$. In region $2(0.06-1 \mathrm{~V})$ the current increases exponentially as $\mathrm{I} \sim \exp$ $(\mathrm{cV})$. The ideality factor (3-4) is determined in this region and the dominating transport mechanism is recombination tunneling. Finally above $1 \mathrm{~V}$ (region 3 ) the current follows a power law $\left(I \sim V^{2.5}\right)$, indicating a space-charge-limited current transport mechanism. Space-charge-limited current (SCLC) and at least one of the other regions observed in the present study have been reported in different $\mathrm{n}-\mathrm{ZnO}$ rods/pSi heterojunction $[13,17,20]$ and in Schottky contact to $\mathrm{ZnO}$ rods [14].

Lampert and Mark [21] have developed the single carrier (SCLC) model with the presence of a trap above the Fermi level. As the applied voltage $\mathrm{V}$ is lower than the onset voltage $\mathrm{V}_{\text {on }}\left(\mathrm{V}<\mathrm{V}_{\text {on }}\right)$ the thermally generated carrier density $\mathrm{n}_{o}$ dominates over the injected carrier density and the carrier transit time $\tau_{x}=\mathrm{d}^{2} / \mu \mathrm{V}_{\text {on }}$ (where $\mu$ is the electron mobility and $\mathrm{d}$ is the depletion width) is larger than the dielectric or ohmic relaxation time $\tau_{\Omega}=\varepsilon \varepsilon_{o} / \mathrm{qn}_{\mathrm{o}} \mu$, where $\varepsilon_{o, \mathcal{E}}$ is permeability constant of air and the material. The injected carrier would 
thus undergo dielectric relaxation to maintain the charge neutrality rather than transport across the sample. In this region, the trap levels are not completely filled. For $\mathrm{V}>$ $\mathrm{V}_{\text {on }}$ the carriers transit time is smaller than the dielectric relaxation time $\left(\tau_{x}<\tau_{\Omega}\right)$ and the injected carriers dominate over the thermally generated carriers. The increase of the applied voltage also shifts the quasi-Fermi level towards the conduction band and the effect would be the filling up of the trap at an energy level $E_{c}-E_{t},[17,21]$. At an applied voltage of $\mathrm{V}>V_{\text {TFL }}$ (TFL stands for trap filled limit) all the trap levels are filled and the conduction would become space charge limited and the current follows the Mott and Gurney SCLC expression [22]

$$
J=\left(\frac{9 \varepsilon \varepsilon_{o} \mu A V^{2}}{8 d^{3}}\right),
$$

where $J$ is current density, $\mu$ is field-independent carrier mobility; $\mathrm{d}$ is the thickness of active layer, $A$ is the area, $\varepsilon$ is the dielectric, constant and $\varepsilon_{o}$ is the permittivity of free space.

The trap filled limit voltage $V_{\mathrm{TFL}}$ is given as [21]

$$
V_{\mathrm{TFL}}=\frac{n_{t} q d^{2}}{2 \varepsilon \varepsilon_{o}},
$$

where $N_{t}$ is the concentration of the unoccupied states (trap concentration), located approximately at the estimated effective Fermi level. The effective carrier concentration $n_{o}$ in the active region is given by the expression

$$
\frac{J\left(2 V_{\mathrm{TFL}}\right)}{J\left(V_{\mathrm{TFL}}\right)} \sim \frac{N_{t}}{n_{o}},
$$

where $J\left(V_{\mathrm{TFL}}\right)$ is the current density at $V_{\mathrm{TFL}}$ and $J\left(2 V_{\mathrm{TFL}}\right)$ is the current density at a voltage twice the $V_{\mathrm{TFL}}$. From the calculated value of $\mathrm{n}_{\mathrm{o}}$, the position of the effective Fermi level (quasi-Fermi level) can be estimated by the expression:

$$
n_{o}=N_{c} e^{\left(E_{F}-E_{c}\right) / k T}
$$

The position of the deep-level state is taken as being within an energy of few $k T$ from the effective Fermi level.

The slow rise in the current at low voltages is an indication of a distribution of states in the energy gap. When all these states are filled with carriers, the current rises rapidly to the space-charge-limited value. Deep-level parameters were calculated from the experimental $V_{\mathrm{TFL}}$ at RT. In these calculations the depletion region thickness $(1.2 \mu \mathrm{m})$ at zero bias capacitance was used as the active layer thickness. The values of $n_{o}, N_{t}$ and the location of the deep level states (radiative defect) below the conduction band were obtained to be $3.4 \times 10^{17} \mathrm{~cm}^{-3}, 4.4 \times 10^{18} \mathrm{~cm}^{-3}$, and $\sim 0.24 \pm 0.02 \mathrm{eV}$, respectively. The deep level states observed are in agreement with the reported data for zinc interstitial $\left(\mathrm{Zn}_{\mathrm{i}}\right)$ level which is theoretically located at $0.22 \mathrm{eV}$ below the conduction band [23]. Recently it was reported that the violet emission originates due to $\mathrm{Zn}_{\mathrm{i}}$ [24]. In addition, according to the full potential linear muffin-tin orbital method-based calculations, the transition energy from $\mathrm{Zn}_{\mathrm{i}}$ level to the valance band in $\mathrm{ZnO}$ corresponds to $3.1 \mathrm{eV}$ [25]. This agrees well with our experimental results. The extracted transition energy from the observed trap $\left(\mathrm{Zn}_{\mathrm{i}}\right)$ to valance band is $3.13 \pm 0.02 \mathrm{eV}$. Several groups reported that the deep level emission (DLE) for the violet, green, and orange red are due to zinc interstitial $\left(\mathrm{Zn}_{\mathrm{i}}\right)$, oxygen vacancies $\left(\mathrm{V}_{\mathrm{o}}\right)$, and oxygen interstitials $\left(\mathrm{O}_{\mathrm{i}}\right)$, respectively $[24,26]$.

\section{Conclusions}

In summary, the current transport mechanism of $\mathrm{ZnO}$ rods/p-SiC has been discussed with the $I-V$ curve using energy band diagram, which illustrates that the current transport mechanism exhibits three different regimes. The tunneling mechanism via deep-level states is the main conduction process at lower applied voltage, while spacecharge-limited current conduction dominated the current transport at higher applied voltage. Deep-level parameters effective carrier concentration, trap concentration and the energy of the trap were calculated. The deep-level state (radiative defect) observed is attributed by zinc interstitial $\left(\mathrm{Zn}_{\mathrm{i}}\right)$, responsible for the violet emission.

\section{References}

[1] M. Willander, O. Nur, Q. X. Zhao, et al., "Zinc oxide nanorod based photonic devices: recent progress in growth, light emitting diodes and lasers," Nanotechnology, vol. 20, no. 33, Article ID 332001, 2009.

[2] D. C. Look, "Recent advances in $\mathrm{ZnO}$ materials and devices," Materials Science and Engineering B, vol. 80, no. 1-3, pp. 383$387,2001$.

[3] C. Klingshirn, "ZnO: from basics towards applications," Physica Status Solidi, vol. 244, no. 9, pp. 3027-3073, 2007.

[4] C.-Y. Chang, F.-C. Tsao, C.-J. Pan et al., "Electroluminescence from $\mathrm{ZnO}$ nanowire/polymer composite $p$ - $n$ junction," Applied Physics Letters, vol. 88, no. 17, Article ID 173503, 3 pages, 2006.

[5] Z. L. Wang, " $\mathrm{ZnO}$ nanowire and nanobelt platform for nanotechnology," Materials Science and Engineering R, vol. 64, no. 3-4, pp. 33-71, 2009.

[6] A. Wadeasa, O. Nur, and M. Willander, "The effect of the interlayer design on the electroluminescence and electrical properties of $\mathrm{n}-\mathrm{ZnO}$ nanorod/p-type blended polymer hybrid light emitting diodes," Nanotechnology, vol. 20, no. 6, Article ID 065710, 2009.

[7] D. M. Bagnall, Y. F. Chen, M. Y. Shen, Z. Zhu, T. Goto, and T. Yao, "Room temperature excitonic stimulated emission from zinc oxide epilayers grown by plasma-assisted MBE," Journal of Crystal Growth, vol. 184-185, pp. 605-609, 1998.

[8] A. Kolmakov and M. Moskovits, "Chemical sensing and catalysis by one-dimensional metal-oxide nanostructures," Annual Review of Materials Research, vol. 34, pp. 151-180, 2004.

[9] Z. L. Wang, "Zinc oxide nanostructures: growth, properties and applications," Journal of Physics Condensed Matter, vol. 16, no. 25, pp. R829-R858, 2004.

[10] E. Lai, W. Kim, and P. Yang, "Vertical nanowire array-based light emitting diodes," Nano Research, vol. 2, no. 1, pp. 123$128,2008$.

[11] H. Noor, P. Klason, O. Nur, Q. Wahab, M. Asghar, and M. Willander, "Time-delayed transformation of defects in zinc 
oxide layers grown along the zinc-face using a hydrothermal technique," Journal of Applied Physics, vol. 105, no. 12, Article ID 123510, 5 pages, 2009.

[12] A. El-Shaer, A. Bakin, E. Schlenker et al., "Fabrication and characterization of $\mathrm{n}-\mathrm{ZnO}$ on $\mathrm{p}$-SiC heterojunction diodes on $4 \mathrm{H}-\mathrm{SiC}$ substrates," Superlattices and Microstructures, vol. 42, no. 1-6, pp. 387-391, 2007.

[13] J. D. Ye, S. L. Gu, S. M. Zhu et al., "Electroluminescent and transport mechanisms of $n-\mathrm{ZnO} / p$-Si heterojunctions," Applied Physics Letters, vol. 88, no. 18, Article ID 182112, 3 pages, 2006.

[14] P. Klason, O. Nur, and M. Willander, "Electrical characteristics and stability of gold and palladium Schottky contacts on $\mathrm{ZnO}$ nanorods," Nanotechnology, vol. 19, no. 47, Article ID 475202, 2008.

[15] A. C. Mofor, A. Bakin, U. Chejarla et al., "Fabrication of $\mathrm{ZnO}$ nanorod-based p-n heterojunction on $\mathrm{SiC}$ substrate," Superlattices and Microstructures, vol. 42, no. 1-6, pp. 415-420, 2007.

[16] A. Henry, J. Hassan, J. P. Bergman, C. Hallin, and E. Janzén, "Thick silicon carbide homoepitaxial layers grown by CVD techniques," Chemical Vapor Deposition, vol. 12, no. 8-9, pp. 475-482, 2006.

[17] X. D. Chen, C. C. Ling, S. Fung et al., "Current transport studies of $\mathrm{ZnO} / \mathrm{p}$-Si heterostructures grown by plasma immersion ion implantation and deposition," Applied Physics Letters, vol. 88, no. 13, Article ID 132104, 3 pages, 2006.

[18] M. W. Allen and S. M. Durbin, "Influence of oxygen vacancies on Schottky contacts to ZnO," Applied Physics Letters, vol. 92, no. 12, Article ID 122110, 3 pages, 2008.

[19] D. T. Quan and H. Hbib, "High barrier height Au/n-type InP Schottky contacts with a $\mathrm{PO}_{\mathrm{x}} \mathrm{N}_{\mathrm{y}} \mathrm{H}_{\mathrm{z}}$ interfacial layer," SolidState Electronics, vol. 36, no. 3, pp. 339-344, 1993.

[20] N. Koteeswara Reddy, Q. Ahsanulhaq, J. H. Kim, and Y. B. Hahn, "Behavior of $n-\mathrm{ZnO}$ nanorods/ $p$-Si heterojunction devices at higher temperatures," Applied Physics Letters, vol. 92, no. 4, Article ID 043127, 3 pages, 2008.

[21] M. A. Lampert and P. Mark, Current Injection in Solids, Academic Press, New York, NY, USA, 1970.

[22] N. F. Mott and R. W. Gurney, Electronic Processes in Ionic Crystals, Oxford University Press, Oxford, UK, 1940.

[23] E. G. Bylander, "Surface effects on the low-energy cathodoluminescence of zinc oxide," Journal of Applied Physics, vol. 49, no. 3, pp. 1188-1195, 1978.

[24] C. H. Ahn, Y. Y. Kim, D. C. Kim, S. K. Mohanta, and H. K. Cho, "A comparative analysis of deep level emission in $\mathrm{ZnO}$ layers deposited by various methods," Journal of Applied Physics, vol. 105, no. 1, Article ID 013502, 5 pages, 2009.

[25] H. Zeng, Z. Li, W. Cai, and P. Liu, "Strong localization effect in temperature dependence of violet-blue emission from $\mathrm{ZnO}$ nanoshells," Journal of Applied Physics, vol. 102, no. 10, Article ID 104307, 4 pages, 2007.

[26] A. B. Djurišić, Y. H. Leung, K. H. Tam et al., "Defect emissions in ZnO nanostructures," Nanotechnology, vol. 18, no. 9, Article ID 095702, 2007. 

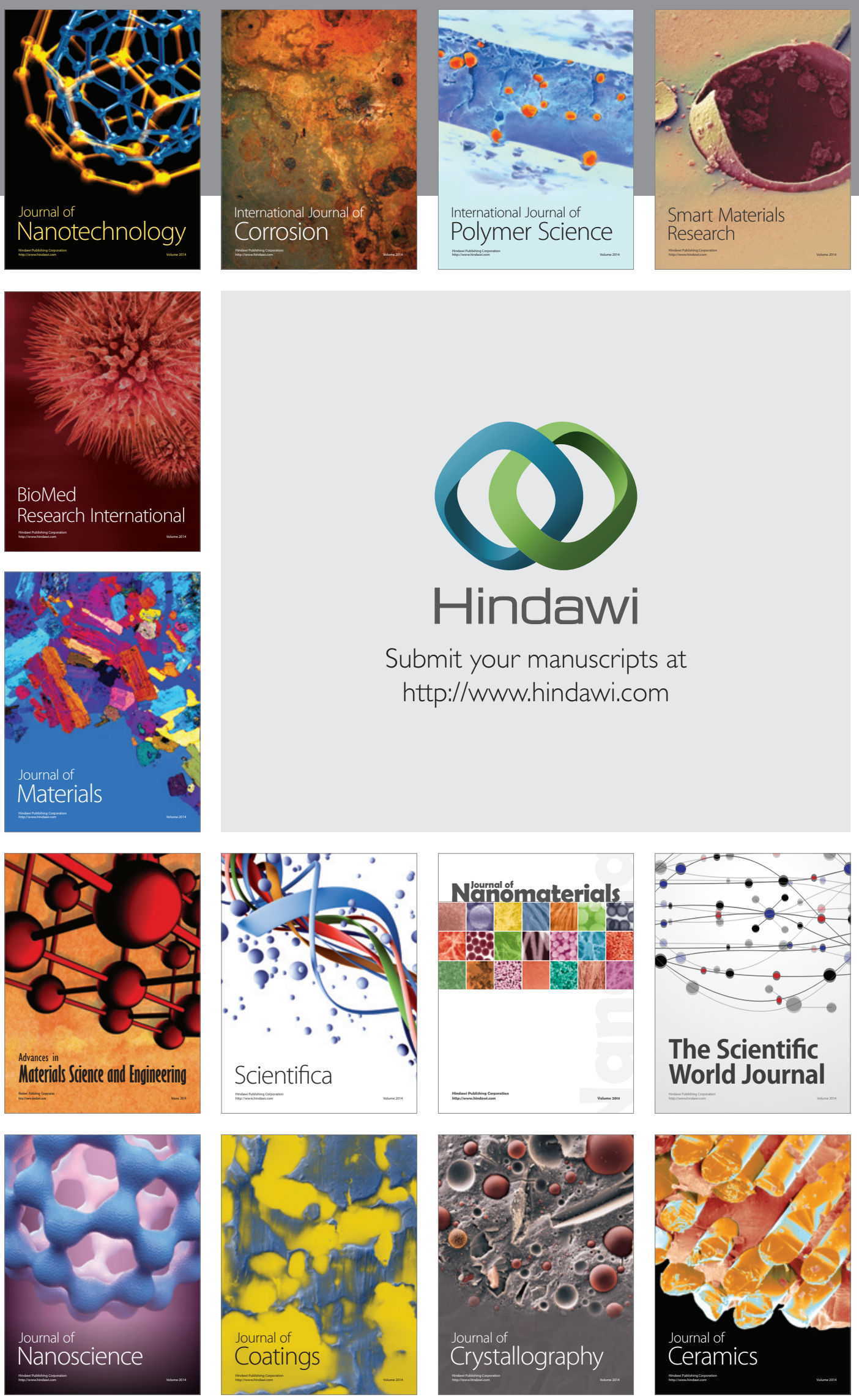

The Scientific World Journal

Submit your manuscripts at

http://www.hindawi.com

\section{World Journal}

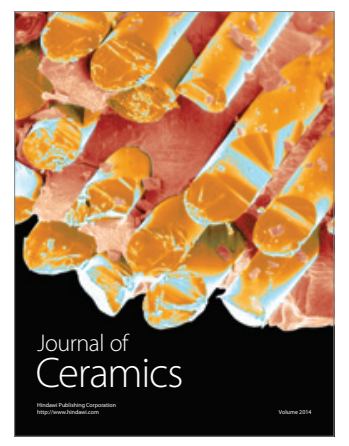

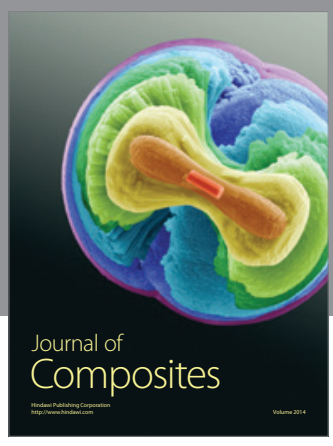
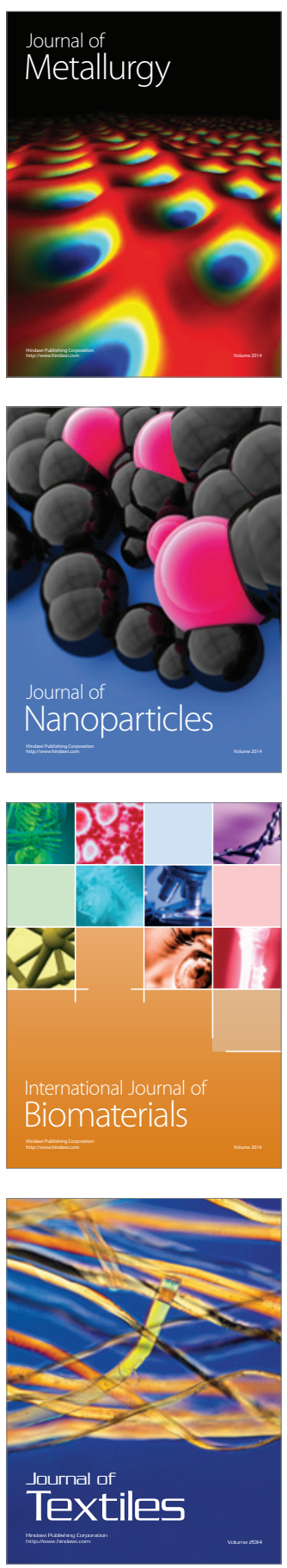